\title{
Age ang Provenance of Taipinglinchang Formation from late Mesozoic in Sunwu-Jiayin Basin of Northeast China: Implication for regional tectonic evolution XIAOYU JIA ${ }^{1}$, FUHONG GAO ${ }^{2}$, MING XIU ${ }^{3}$ \\ ${ }^{1}$ College of Earth Sciences, Jilin University, China jiaxy18@mails.jlu.edu.cn \\ ${ }^{2}$ College of Earth Sciences, Jilin University, China gaofh@jlu.edu.cn \\ ${ }^{3}$ College of Earth Sciences, Jilin University, China xiuming17@mails.jlu.edu.cn
}

LA-ICP-MS U-Pb dating of zircons from the Cretaceous Taipinglinchang Formation in the Sunwu-Jiayin Basin, Northeast China, is presented in order to constrain the provenances. Most of zircons from the Taipinglinchang Formation are euhedral-subhedral in shape and display striped absorption or oscillatory zoning in CL images, implying their magmatic origin. The dating results indicate that detrital zircons from sandstone in the Taipinglinchang Formation yielded age populations of 98Ma, 101.3Ma, 185Ma, 217Ma, 490Ma, 500Ma.

According to the above dating results, it can be determined that the Taipinglinchang Formation formed in Late Cretaceous of the Late Mesozoic. Based on the similarity of age populations of detrital zircons from sandstone in the Taipinglinchang Formation, it is suggested that provenance of the Taipinglinchang Formation is mainly derived from the Late Mesozoic geological bodies around the sedimentary basin and the Early Paleozoic granitic rocks in Jiamusi Range Massif is the secondary provenance. Additionally, the study of zircons chronology shows that there are many magmatic events in the study area from Early Paleozoic to Late Mesozoic. 